\title{
Epitaxial Grain Growth During Surface Modification of Friction Stir Welded Aerospace Alloys by a Pulsed Laser System
}

\author{
P. Ryan ${ }^{1, a}$, P.B.Prangnell ${ }^{1, b}$ and S.W. Williams ${ }^{2, c}$ \\ ${ }^{1}$ Manchester Materials Science Centre, The University of Manchester, Grosvenor St. Manchester, \\ M1 7HS, UK. \\ ${ }^{2}$ Welding Engineering Research Centre, Cranfield University, Cranfield, Bedfordshire, MK43 OAL, \\ UK. \\ ap.ryan@postgrad.manchester.ac.uk, ${ }^{\mathrm{b}}$ philip.prangnell@manchester.ac.uk, \\ cs.williams@cranfield.ac.uk
}

Keywords: laser surface melting (LSM), rapid solidification, epitaxial growth, dispersoid particles, equiaxed zone.

\begin{abstract}
The liquid film re-growth behaviour resulting from pulsed laser surface melting (LSM) has been investigated for typical 2xxx, and 7xxx aerospace alloys, both on parent plate and friction stir welded (FSW) joints. In Zr free alloys, as a result of the high growth rate and steep thermal gradient, the melted layer re-grew with a stable front, epitaxially, from the parent subsurface grains. This caused a thin coarse grained solidified layer to form over the parent material, thermomechanically affected zone (TMAZ) and heat affected zone (HAZ), and fine columnar grains to develop over the FSW nugget zone of the same order in width as the nugget grain size. In the case of the $\mathrm{Zr}$ containing alloys, a very fine columnar grain structure was found over the entire surface, independent of the subsurface grain structure. This has been shown to occur by growth selection from a band of nanoscale $\mathrm{Al}$ grains epitaxially nucleated on $\mathrm{Al}_{3} \mathrm{Zr}$ dispersoids, at the melt solid interface, that had not fully dissolved in the melt.
\end{abstract}

\section{Introduction}

The aerospace industry currently relies on coating systems containing hexavalent chromium for the protection of aluminium aircraft structures from corrosion. Whilst being highly effective, the chemicals used to produce these coatings are extremely toxic and as a result are being phased out of use. Urgent research is being conducted to find a replacement and one technique that may help to solve this problem, or act as a pre-treatment for welded joints, is laser surface melting (LSM). If the correct parameters are employed, pulsed LSM can be used to form a chemically homogenous layer on the surface of an aluminium alloy. This significantly improves the corrosion properties of the material and could act as a precursor to additional protection systems $[1,2,3]$.

During pulsed-LSM, a laser raster pattern is used to rapidly melt a thin surface layer using multiple overlapping spots. The comparatively massive un-melted substrate acts as a heat sink, drawing energy rapidly away from the surface. The exact cooling rate will vary according to the process conditions, but figures as high as $10^{11} \mathrm{~K} \mathrm{~s}^{-1}$ have been reported [4]. These extremely high cooling rates correspond to a growth front that will advance with velocities of the order of several $\mathrm{ms}^{-1}$, with a high liquid thermal gradient. In this large Peclet number regime the front advances near the point of absolute stability, above which a planar solidification front is seen [5]. This means that the velocity dependent partition coefficient, $\mathrm{k}_{\mathrm{v}} \rightarrow 1$ and the solid that forms will have the same composition as the liquid. Under such conditions it is expected that a chemically homogeneous surface layer will be produced. However, incomplete mixing in the liquid of melted second phase particles may still occur. Grains in the re-solidified layer, would also be expected to re-grow epitaxially from the unmelted substrate [6].

Previous investigations into the effect of pulsed excimer LSM on aluminium aerospace alloys have concentrated on the corrosion properties of the treated layers, with limited 
microstructural investigation [3,7,8]. The aim of this study was to examine in detail the microstructure of the LSM layer, and in particular the grain re-growth behaviour, after excimer surface treatment of typical parent and friction stir welded 2xxx and 7xxx series alloys.

\section{Experimental Procedure}

During this investigation, two $\mathrm{Zr}$ free alloys, 2024-T3 and 7075-T6 and two $\mathrm{Zr}$ containing alloys, 2096-T3 and 7150-T6 were used as bare plate. In addidtion, 2024-T3 was also examined after friction stir welding (FSW). All alloys were in the form of rolled plate. Prior to laser treatment, a small amount of material was milled from the top of all the samples and their surfaces thoroughly cleaned with alcohol. LSM was performed using a Lambda Physik LP315i excimer laser operating at a wavelength of $308 \mathrm{~nm}$ (active medium $\mathrm{XeCl}$ ) and with a pulse length of $25 \mathrm{~ns}$. The laser was scanned across the surface using a raster regime developed to ensure that the entire area was treated as quickly and homogeneously as possible, which subjected each area to 9 overlaid pulses. The pulse repetition rate was such that the layer melted and re-solidified between pulses. The treated regions were examined in cross-section using a Philips XL30 FEGSEM equipped with electron backscattered diffraction (EBSD) and an FEI Tecnai F30 FEGTEM. For SEM and EBSD this involved mounting the samples in a hard, edge retaining, resin. LSM layer cross section TEM samples were prepared using a precision ion polishing system.

\section{Results and Discussion}

Solidification Conditions: By image analysis it was found that the laser parameters used resulted in a melt depth of between 4 and 6 microns. This information enabled the calibration of an analytical model to generate the approximate thermal history experienced during LSM. Using a solution to the heat diffusion equation formulated by Prokhorov et. al. [9], a program was written to calculate time - temperature profiles as a function of depth. By assuming that all material reaching temperatures greater than the boiling point was lost to vapourisation, the speed of the solidification front as a function of depth, could be calculated; shown in Fig. 1 for the minimum and maximum layer thickness. The growth front covers the melt depth of $4-6 \mu \mathrm{m}$ in $2.5 \times 10^{-7}-6.7 \times 10^{-7} \mathrm{~s}$, equivalent to an average cooling rate of approximately $7.8 \times 10^{9}-2.9 \times 10^{9} \mathrm{~K} \mathrm{~s}^{-1}$.

Kurz and Trivedi extended the original Mullins and Sekerka interface stability analysis to identify the critical velocity at which a planar front is stabilised. Using typical values for a binary $\mathrm{Al}$ $-4 \mathrm{wt} . \% \mathrm{Cu}$ alloy, this can be shown to be of the order of $5 \mathrm{~m} \mathrm{~s}^{-1}$ [5]. Fig. 1 shows that the growth front rapidly accelerates to velocities in excess of $20 \mathrm{~m} \mathrm{~s}^{-1}$. It will be moving at velocities above the stability threshold for the vast majority of the process, however, as it is initially below this value there is the possibility of a small amount of fine cellular growth at the very base of the layer.

Fig. 1: Solidification front velocity as a function of position, for the minimum and maximum layer thickness.

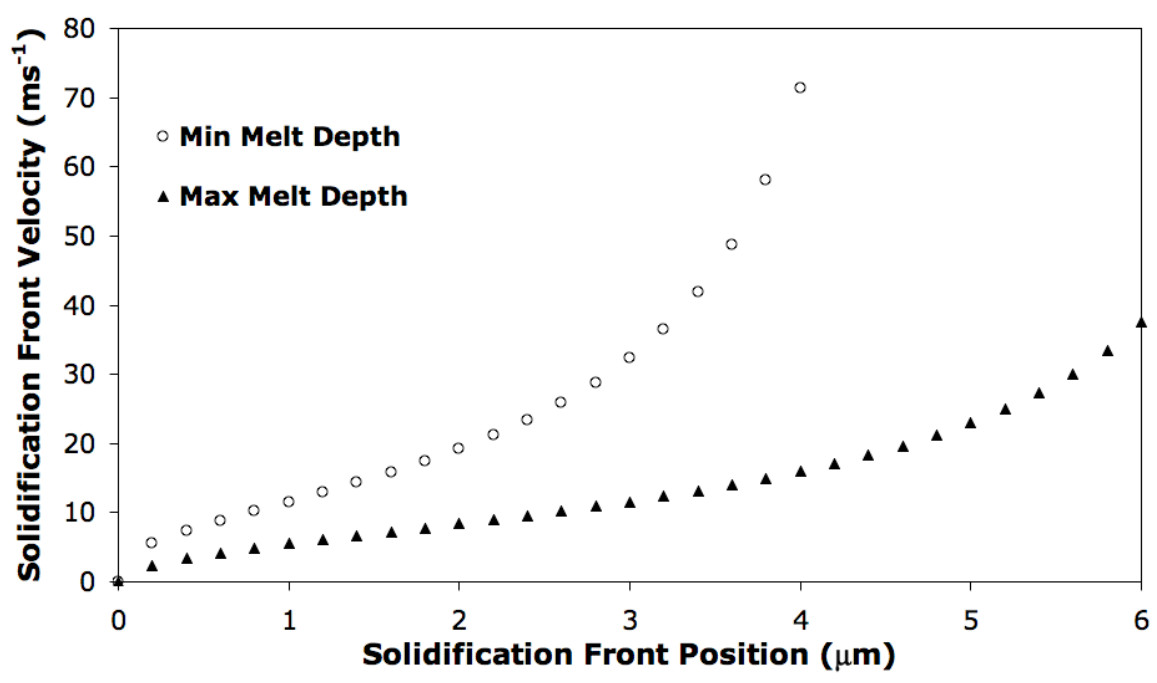


LSM treated Zr Free Alloys: Examples of the re-solidified LSM layer microstructures produced on the parent 2024 (Fig. 2a and 2c) and 7075 (Fig. 2b and 2d) alloys are shown in Fig. 2. No evidence of cellular growth could be found, confirming that solidification occurred with a planar front, as might be expected from the theoretical analysis given above. Although the melted surface layers were far more chemically homogeneous than the substrate, they all contained nearly horizontal bands, which corresponded to the overlapping melt layers from the rastered individual laser pulses (arrowed in Fig. 2c). The solute ( $\mathrm{Mn}$ and $\mathrm{Cr}$ ) rich liquid from melted dispersoid particles could also be seen to have not fully dispersed close to the base of the layer (Fig. 2c), and from large Fe rich primary particles to about $60 \%$ of the layer thickness (Fig. 2a). The distribution of solute from the melted second phase particles gives evidence of considerable lateral fluid flow, due to the action of the recoil pressure of evaporation, but with such short melt durations there is insufficient time for the solute to fully disperse by diffusion. This will lead to local regions where the solid solution has been extended to very high supersaturations. The LSM layer microstructure over the FSW weld zones was seen to be very similar, with the exception of the re-solidified grain structure which will be discussed further below.

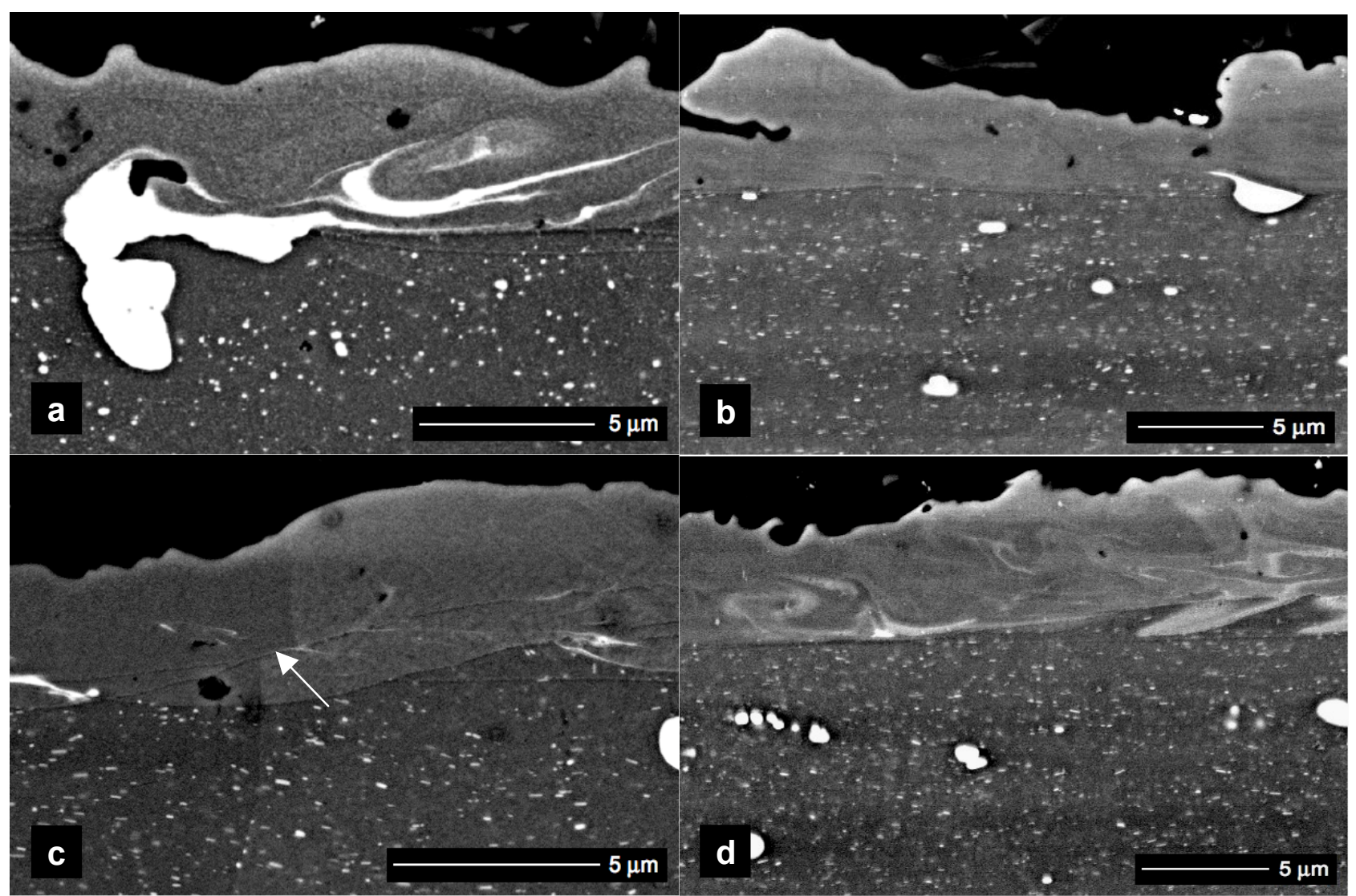

Fig. 2 SEM back scattered images showing examples of the re-solidified LSM layer microstructures on the parent alloys; (a) and (b) the full layer in the 2024 and 7075 alloys, and in (c) the individual pulse layers which have produced a step in the grain boundary (arrow) in 2024, and in (d) a region rich in solute from partially dispersed particles in 7075 .

From the high resolution EBSD analysis, shown in Fig. 3a and the images in Fig. 2, the grain structures of the re-solidified surface layers for the two $\mathrm{Zr}$ free alloys were found to behave identically. It can be seen that the subsurface grains have re-grown into the melted layer in the direction of the surface, virtually reproducing the subsurface grain size. This behaviour is normally referred to as epitaxial growth and is found in situations where the substrate and liquid are effectively the same material, resulting in no energy barrier to nucleation, and when there is no 
possibility of undercooling occurring ahead of the growth front (such as near the fusion boundary in welding [6]). In the case of the parent alloys (Fig. 3a), because the grain size in the substrate is large, the grain structure of the re-solidified surface layer is virtually indistinguishable from that of the substrate. However, there is some evidence of individual grains over-growing their neighbors (e.g. arrow in Fig. 3a) and at higher magnifications lateral steps in the vertical grain boundaries can be seen on crossing the horizontal band boundaries resulting from overlapping pulses (Fig. 2c).

Traversing across the zones of the weld, the HAZ and TMAZ grain re-growth behaviour was similar to the parent material, while the layer above the nugget had a markedly different grain structure (Fig. 3b). Here again, as for the parent material, the subsurface grains grew back into the melted layer following the maximum thermal gradient. However, in this case the extremely fine ( 2 $\mu \mathrm{m}$ ) nugget zone grain size, relative to the layer thickness, led to the formation of an equally fine columnar grain structure. The EBSD map in Fig. 3b confirms that this structure is the result of directional growth of fine columnar grains with a stable front, rather than a cellular solidification structure.

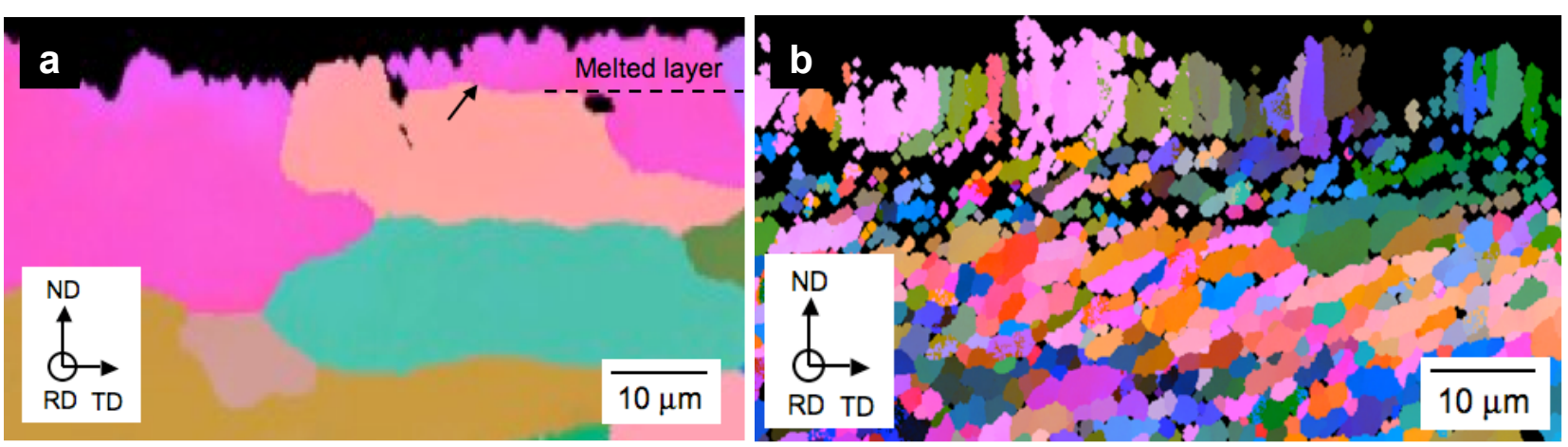

Fig. 3 High resolution Euler contrast EBSD maps of the grain structures in the LSM layers on, (a) 2024 parent plate and (b) over the FSW weld nugget zone in 2024

LSM treated Zr Bearing Alloys: Comparison of the Euler contrast EBSD maps in Fig. 3a and 4 reveals a markedly different solidification structure within the LSM layer for the Zr bearing parent alloys. For the 2096 and 7150 alloys, which contain metastable $\beta^{\prime} \mathrm{Al}_{3} \mathrm{Zr}$ dispersoids, the LSM layer consisted of extremely fine columnar grains that do not relate to the subsurface grain structure and can thus not have formed by epitaxial nucleation from the unmelted substrate. The fact that the same behavior is observed for $\mathrm{Zr}$ containing alloys from two different alloy series, suggests that this is a general effect that can be related to the presence of $\mathrm{Al}_{3} \mathrm{Zr}$ dispersoid particles within these materials.

Fig. 4 Example Euler contrast EBSD map of the grain structure in the LSM layer in the $\mathrm{Zr}$ bearing 7150 (the dark regions are un-indexed points).

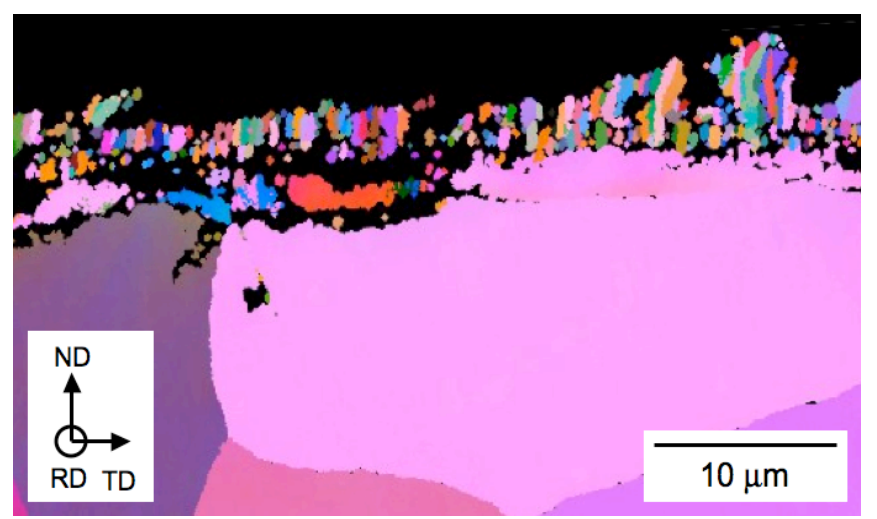

One possible explanation for the formation of the fine columnar structure in the $\mathrm{Zr}$ containing alloys is that the grains did not nucleate epitaxially from the unmelted substrate, but rather heterogeneously on the $\mathrm{Al}_{3} \mathrm{Zr}$ dispersoid particles, that do not fully melt near the base of the liquid layer. This phase has an FCC L1 2 superlattice crystal structure with a lattice parameter very close to that of pure Al. As a result it can act as a very efficient nucleant of $\alpha-\mathrm{Al}$ [10]. To obtain 
support for this hypothesis, higher resolution analysis of the re-solidified layers was performed by TEM. Fig. 5a shows an overview of the structures seen at the base of the melted layer in the 7150 alloy. Three regions are clearly identifiable; the parent material/HAZ, a band of tiny seed grains $<500 \mathrm{~nm}$ in width, and coarser columnar grains growing upwards towards the surface. It is likely that the columnar grain growth is selective, with those 'seed' grains that have their fast $<100>$ crystallographic direction well aligned to the maximum thermal gradient outgrowing less well aligned grains.
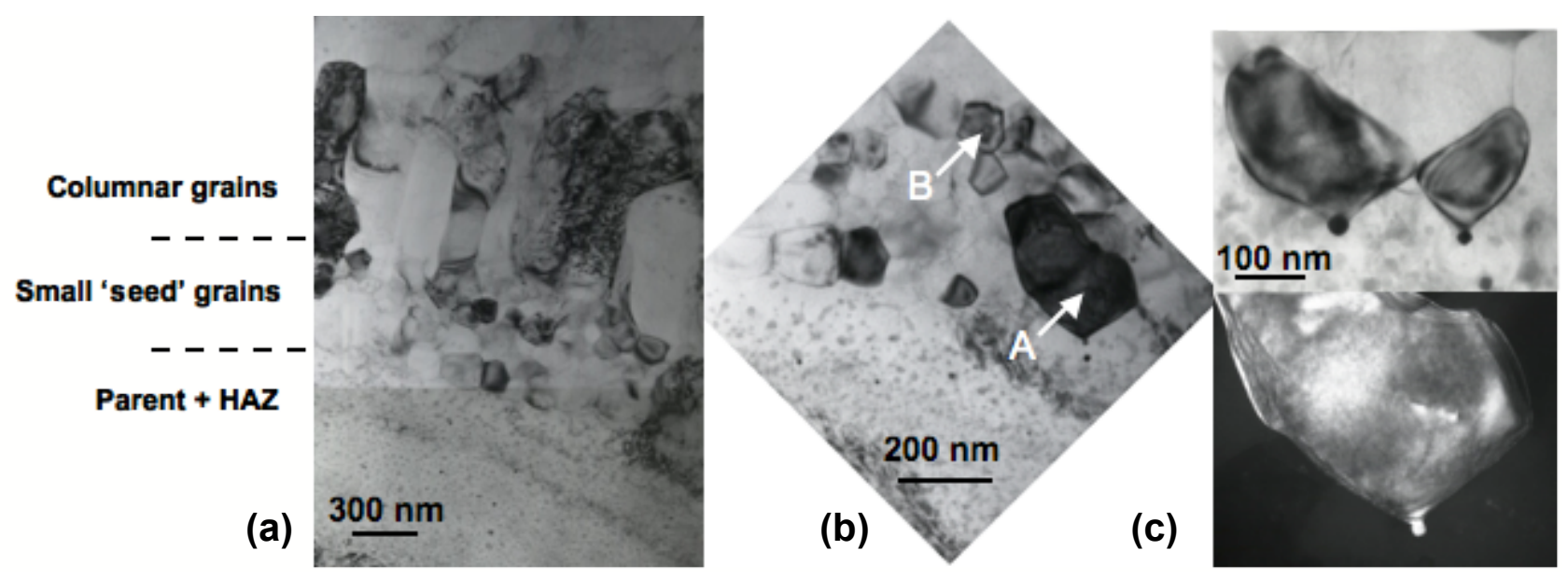

Fig. 5 Cross-sectional TEM images from the fine columnar LSM layer in the 7150 alloy; in (a) three distinctive zones are identified, (b) shows a close up on the seed grain region, where ' $A$ ' denotes a grain that has nucleated from a particle at the base of the melt layer, whilst ' $\mathrm{B}$ ' is a grain that appears to have nucleated ahead of the solid-liquid interface, (c) shows bright field and dark field images of a type A 'seed' grains that has nucleated from particles present at the very base of the melted layer.

Fig. 5b shows a higher magnification view of the 'seed' grain region. From this, two different grain morphologies can be identified. The first, labeled A, appear to have grown from particles, identified as $\mathrm{Al}_{3} \mathrm{Zr}$ dispersoids, present at the very base of the melted region, which may still have been embedded in the parent material. Others, like that labeled B, are equiaxed in shape and have formed ahead of the solidification front. Fig. 5c shows the type A 'seed' grains at higher magnification.

An example of a type B equiaxed 'seed' grain is shown in Fig. 6 which is only $\sim 250 \mathrm{~nm}$ in diameter. It clearly has an $\mathrm{Al}_{3} \mathrm{Zr}$ particle present at its centre. A high-resolution lattice image taken from the particle-grain interface along the [013] zone axis with a fourier transforms from the matrix and particle are shown in Fig. 6b. These images show that the $\alpha$-Al matrix is epitaxial with the $\mathrm{Al}_{3} \mathrm{Zr}$ dispersoid nucleant, which is readily identifiable from its additional superlattice reflection. It is apparent that the $\mathrm{Al}_{3} \mathrm{Zr}$ dispersoids present in the substrate are responsible for nucleating the fine columnar grains seen in the 7150 and 2096 alloys. Due to their high melting point [11], and the rapid thermal cycle, these particles do not fully melt near the base of the liquid layer and can act as powerful nucleants during re-solidification. This mechanism thus appears to be closely related to the fine equaxed grain zone seen at the fusion boundary in welded $\mathrm{Zr}$ and $\mathrm{Li}$ containing alloys [10].

When they originally form in the sold state during homogenization of DC cast billets the $\mathrm{Al}_{3} \mathrm{Zr}$ dispersoids are normally epitaxial with the $\mathrm{Al}$ matrix, but can loose their coherency from the action of migrating boundaries during the TMP cycle required to produce rolled plate. If the dispersoids were still embedded in the Al matrix, when they nucleated the columnar grains, only a limited range of orientations would be produced, which is not the case for the EBSD maps taken from the surface layers (Fig. 4). 

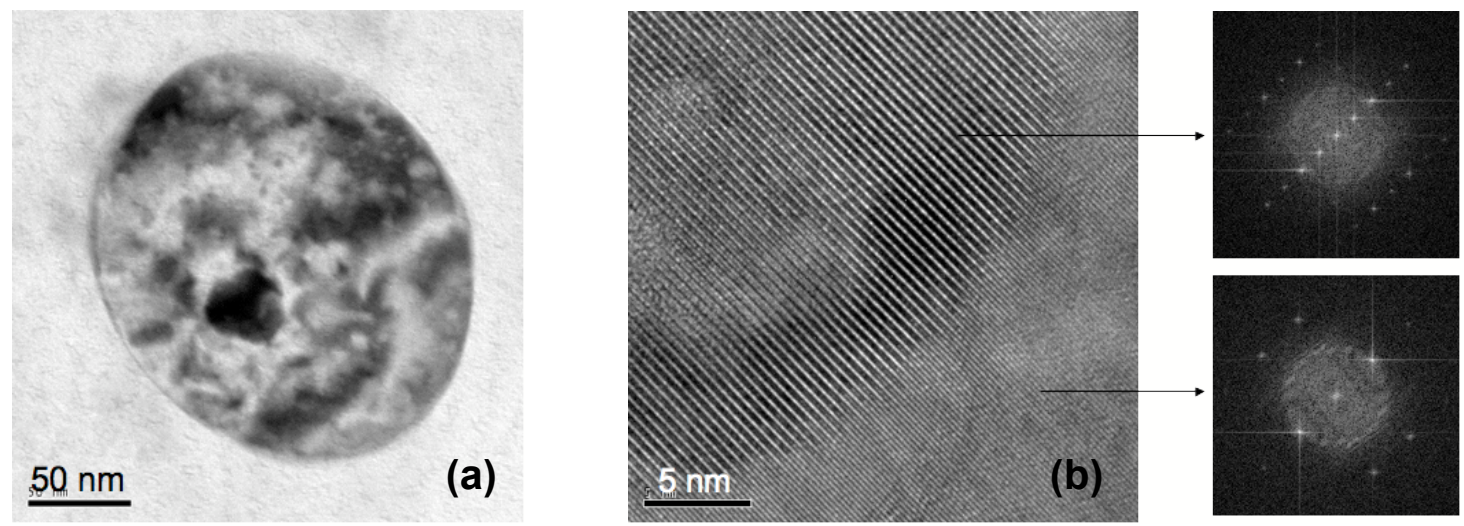

Fig. 6: TEM images of an equiaxed, type B, 'seed' grain. Lattice imaging in (b) indicates the nucleant has a cube-cube relationship to the $\mathrm{Al}$ matrix and a type $\mathrm{L}_{2}$ crystal structure.

Nucleation of the 'seed grains' must mainly occur from detached $\mathrm{Al}_{3} \mathrm{Zr}$ particles that have survived slightly ahead of the growth front. Given the high solidification rate, with no solute partitioning, and large positive thermal gradient, at first sight this appears a surprising scenario as an undercooling would be required ahead of the solid-liquid interface. It is possible that this develops because there is no time for the $\mathrm{Zr}$ released from the partially melted $\mathrm{Al}_{3} \mathrm{Zr}$ particles to disperse, leaving a $\mathrm{Zr}$ rich boundary layer which locally raises the liquids melting point.

\section{Conclusions}

The rapid solidification rate resulting from pulsed excimer laser surface treatment leads to partionless solidification and the chemical homogenisation of the surface. However, the layer can still contain partially melted second phase particles. The re-solidified LSM layers in Zr free alloys (2024 and 7075) grow epitaxially. They mimick the grain size of the unmelted substrate, leading to fine columnar grains forming over FSW nugget regions and coarse grained layers over the parent plate, TMAZ and HAZ. In Zr containing alloys (2096 and 7150), fine columnar grains were observed, irrespective of the substrate grain structure. TEM investigation showed that these grains nucleated heterogeneously and epitaxially from the $\mathrm{L1}_{2} \mathrm{Al}_{3} \mathrm{Zr}$ dispersoid particles that had survived in the melt, close to the melt-solid interface.

\section{Acknowledgements}

The authors would like to acknowledge Eirian Siggs and Stephen Morgan of BAE Systems for the creation of LSM samples and Airbus UK and the EPSRC for financial support.

\section{References}

[1] P.L. Bonora, et. al.: Thin Solid Films. Vol. 81 (1981), p 339-345

[2] K.G. Watkins, M.A. McMahon, W.M. Steen: Mat. Sci. and Engineering A231 (1997), p 55-61

[3] C.P. Chan, T.M. Yue, H.C. Man: Journal of Materials Science. Vol. 38 (2003), p 2689-2702

[4] R. Li, et. al.: Surface and Coatings Technology. Vol. 81 (1996), p 290-296

[5] W. Kurz, D.J. Fisher: "Fundamentals of Solidification", Trans Tech Publishing (1992)

[6] S.A. David, J.M. Vitek: International Materials Reviews. Vol. 34 (1989), p 213-245

[7] C.P. Chan, T.M. Yue, H.C. Man: Materials Science and Technology. Vol. 18 (2002), p 575-580

[8] T.M. Yue, C.F. Dong, L.J. Yan, H.C. Man: Materials Letters. Vol. 58 (2004), p 630-635

[9] A.M. Prokhorov, et. al.: "Laser Heating of Metals", Adam Hilger (1990)

[10]A. Gutierrez, J. Lippold, W. Lin: Materials Science Forum. Vol. 217-222 (1996), p 1691-1696

[11]J. Murray, et. al.: Journal of Phase Equilibria. Vol. 13 (1992), p 277-291 
Aluminium Alloys 2006

doi:10.4028/www.scientific.net/MSF.519-521

Epitaxial Grain Growth during Surface Modification of Friction Stir Welded Aerospace Alloys by a Pulsed Laser System

doi:10.4028/www.scientific.net/MSF.519-521.1169 